\title{
Combining Multicultural Management and Diversity Into One Course on Cultural Competence
}

\author{
MARY LOU EGAN \\ MARC BENDICK, JR.
}

Bendick and Egan Economic Consultants, Inc.

There can be little debate that culture-the multiple characteristics and backgrounds that shape individuals' and organizations' identities, perceptions, attitudes, and behavior-strongly influences the success of business enterprises today. Intergroup conflict constantly threatens the ability of both domestic and global firms to operate efficiently, cooperatively, and fairly. Did a merger between a Japanese-owned firm and an American-owned firm fail because of inferior products and inappropriate pricing or because the managers were personally incompatible and the organizations' operating styles too disparate? Did a company's efforts to advance women into management fail because the women were not up to the challenge or because the work environment undermined their performance or perceived performance? Business educators cannot simply teach undergraduate and graduate students that cultural differences matter. They must equip students to understand how cultural differences work and thus how to turn cultural competence into a competitive advantage.

Unfortunately, undergraduate and graduate courses in multicultural management (also called "cross-cultural management") tend to fall short of this goal. We identify cultural management skills required for success in today's business environment, then examine gaps between those target competencies and current teaching in multicultural management, and the source of those gaps in the courses' conceptual foundations. We suggest improving these courses using concepts from, among other places, "domestic" diversity management courses. In fact, we propose to improve both types of courses by merging them into a unified course designed around the border-erasing concept of cultural competence.

\section{WHATT MANAAGERS NEED TO KNOW}

The Association to Advance Collegiate Schools of Business International (AACSB, 2007: 1) directs business schools to prepare their students to work in an environment of strong global economic forces, wide differences in organizational and cultural values, and growing cultural diversity among employees and customers. The personal competencies responding to these requirements include flexibility, resourcefulness, tolerance for ambiguity, and vision, as well as cultural self-awareness, cultural consciousness, and multicultural leadership (Cant, 2004: 177; see also Senyshyn, 2002).

Managers typically apply these competencies at the individual, work group, and organizational levels, for example in dealing with customers and suppliers, conducting negotiations, or staffing joint ventures. Accordingly, undergraduate and graduate business education cannot simply make students aware that personal and organizational differences are important. It must equip students to understand and respond to exactly what, when, how, and how much culture matters in such practical interpersonal and organizational situations.

\section{MULTICULTURAL MIS-EDUCATION}

Courses in multicultural management are commonly taught within the academic field of international business (IB). In the early stages of internationalizing business curricula, schools often separate "international" from "domestic" courses to sidestep retooling domestically oriented faculty, relying instead on professors who are international specialists (Albers-Miller, Sigerstad, \& Straughan, 2000: 56-57). Those specialized professors, in turn, have sought to establish IB as a dis- 
cipline in its own right, differentiated from functional fields such as marketing, finance, and strategy with which its courses often overlap. To support this search for identity, IB has traditionally interpreted the term culture to mean national cultures exclusively and has emphasized differences among nations as a central, unique focus of the field (Rosenzweig, 1994: 4; Hambrick \& Chen, 2008: 47-49).

This focus is particularly evident in IB research distilling national cultures into a small number of universal dimensions. Widely cited studies in this tradition analyze how nations differ in overall culture (Hofstede, 1980, 1991); relationship orientations (Trompenaars, 1994); and leadership (House, Javidan, Hanges, \& Dorfman, 2002). For example, Hofstede's pioneering research used surveys of 88,000 IBM employees worldwide to classify 40 nations along four cultural dimensions: individualismcollectivism, power distance, uncertainty avoidance, and masculinity-femininity. His work has inspired literally thousands of follow-up studies (Kirkman, Lowe, \& Gibson, 2006).

Such research has long been criticized for oversimplifying complex cultures, generalizing from $a$ limited number of firms, assuming that culture and social structures are static, and ignoring withincountry heterogeneity (McSweeney, 2002; Sivakumar \& Nakata, 200l; Kirkman et al., 2006: 286; Tung, 2008). These same criticisms apply to multicultural management courses discussing this research, especially when the courses address practical business situations. As noted earlier, managers work primarily at the interpersonal, work group, or organizational level rather than the national level. Hofstede himself has warned against applying national cultural dimensions to subnational levels (Hofstede, 1991: 253). Nevertheless, Kirkman et al.'s (2006: 288) review of 180 empirical studies incorporating Hofstede's framework found that the majority ignore this warning to analyze individuals, groups, or firms.

Empirical findings from such studies themselves suggest the inappropriateness of such applications. When national average characteristics are used to predict or explain the behavior of individuals, groups or firms, "the relatively low amount of variance explained by the cultural values in many studies underscores the existence of the many other forces besides [national] culture [which] determine the behavior and attitudes of individuals in societies" (Kirkman et al., 2006: 313). For instance, Palich, Hom, and Griffeth (1995) found that Hofstede's cultural dimensions accounted for only $2.7 \%$ of the person-to-person variance in employee commitment. Thus, the research itself teaches that, in practical business applications, national cultures do not matter very much.

Content routinely taught in "domestic" diversity management education sensitizes us to recognize such applications of national cultural characteristics to individuals, groups, or organizations as stereotyping. The psychological and sociological processes are essentially no different whether the stereotype is based on national cultures or race or gender cultures. Extensive behavioral science research demonstrates that, in dealing with individuals or small groups, behavior can be effectively understood and predicted only by assessing individuals or groups themselves, taking account of the full range of their specific characteristics and contexts (Gilovich, Keltner, \& Nisbett, 2006; Bielby, 2000; Jones, 1997).

Ignoring this well-established principle, inappropriate application in the classroom of national cultural generalizations continues to be urged by many IB researchers and teachers. For instance, one recent publication from the Global Leadership and Organizational Behavior Effectiveness (GLOBE) study discusses a hypothetical American executive leading hypothetical work teams in Brazil, France, Egypt, and China to "show the range of leadership responses that should be effective in each cultural setting" (Jarvidan, Dorfman, Sully de Luque, \& House, 2006: 73). Among other advice, the article states that in the French team, "[t]heir low humane orientation culture may mean that they are not particularly interested in being supportive of others, even in the same organization" (Javidan et al., 2006: 67).

When GLOBE researchers were challenged with the idea that such subnational applications of national-level findings represent stereotyping (Graen, 2006: 95), they denied that such statements "would cause serious students of culture, or intercultural managers, to form stereotypes, but rather to seek out information beyond the first GLOBE book" (House et al., 2006: 109). But undergraduate and graduate business students, however intelligent, are rarely "serious students" in the sense of reading underlying research studies and understanding the fine points of research methodology. Instead, these students more typically retain and apply "take-away lessons" summarized in lectures and textbooks.

Unfortunately, examples of stereotype-ridden take-away lessons in widely used instructional materials in multicultural management are easy to find. For instance, one teaching module on international negotiations prepared by a leading IB teaching support center offers the advice that "Scandinavians tend to be uncomfortable with much bargaining at all" (MSU, 2007). A manager 
who had been taught such material could hardly be blamed if he blunders into a sales presentation to Ikea intending to hold firm on prices because Scandinavians are culturally programmed to avoid the confrontation involved in hard bargaining. When he encounters the actual Ikea buyer- $a$ Greek raised in Canada, trained in the Harvard negotiating program, with 20 years' experience as a buyer in China-this former student will soon rue his mis-education. Simple stereotypes about national cultures have not prepared him to deal with this culturally complex individual in a culturally complex situation.

\section{Simple stereotypes about national cultures have not prepared him to deal with this culturally complex individual in a culturally complex situation.}

Content routinely taught in "domestic" diversity management courses makes us aware that cultural generalizations do harm beyond simply encouraging students to stereotype. When generalizations are applied to cultural groups of which the person making the application does not consider himself a part, negative content tends to turn simple cultural misunderstandings into intergroup hostility in the form of "us versus them" and "we are superior to them." Social psychology labels this process prejudice, while multicultural management more commonly refers to ethnocentrism, the tendency to think the culture of one's own group or nation is superior to that of others (Drever, 1952: 86).

One recent review of 16 widely used, multiedition IB and multicultural management texts (Tipton, 2006: 10) found "some truly remarkable errors of fact and interpretation," creating a negative view of the foreign "other." For example:

- The British habit of automatically lining up on the sidewalk when waiting for a bus reflects "the deep cultural desire to lead neat and controlled lives" (Ball et al., 2006: 178 in Tipton, 2006: 11).

- South Korean business practice reflects Confucian thought in their rigid organizational structure and unswerving reverence for authority. As a result, "Korean employees do not question strict chains of command" (Wild, Wild, \& Han, 2006: 65 in Tipton, 2006: 11).

The author of that review argues that the common message of such statements is that only a "certain set of values is appropriate for managers, and the texts' implicit purpose was to inculcate those values" (Tipton, 2006: 13). In this interpretation, multicultural management texts deliberately portray cultural "others" negatively to mold students into Western-style managers, rather than equipping them to understand cultural differences and engage those differences in a neutral way.

We offer a more benign explanation: an incremental approach to updating textbooks which, rather than purging incorrect or obsolete content, simply adds new material and additional explanations. This process results in side-by-side contradictory information, which creates confusion and ambiguity. Psychological research has established that when students encounter contradictory or ambiguous information about groups other than their own, they are likely to remember the negative version. For example, research on in-group bias has established that members of one's own group tend to be granted the benefit of the doubt in circumstances where members of other groups are not; the same behavior may be given a different interpretation depending on whether the person is a member of the perceiver's group; and evaluators tend to judge members of groups to which they do not belong more extremely than members of their own group (Gilovich et al., 2006; Jones, 1997).

Many instructors in multicultural management undoubtedly caution their students against what IB master teachers label the "ugly risk" of stereotyping (Boyacigiller, Goodman, \& Phillips, 2003: 5). However, teaching materials in the field commonly de-emphasize, ignore, or contradict such warnings, and it is reasonable to assume that many classroom instructors do the same.

Those holding fast to the value of teaching national cultural frameworks argue that, despite these potential drawbacks, national generalizations provide a useful starting point to which students should be exposed-albeit with caveats and added nuances. For example, one researcher suggests a "cautious" teaching approach that presents cultural generalizations as one perspective among many, updates the material frequently, and avoids normative judgments (World Bank, 2007: 39). The contrary position argues that even when cautiously introduced, national cultural fromeworks rigidify attitudes, limit perceptions, and reinforce cultural divides. Thus, when this researcher applied his "cautious" approach in training internationally sophisticated World Bank staff, many trainees rejected even the cautiously taught material as inaccurate, prejudicial, distracting from more important concerns, and encouraging a formalistic, distornt, and static way of approaching differences which enhanced "us-vs.-them" attitudes (World Bank, 2007: 39-40).

Social psychology research, to which students are exposed in well-taught diversity management 
courses, supports these trainees' reactions. As a universal tendency in everyone's mental life, stereotyping requires constant vigilance to control. For example, research has demonstrated that individuals tend to seek out information confirming stereotypes at a greater rate than information contradicting them; when information is ambiguous, individuals fit it to confirm stereotypical expectations; even when individuals are explicitly informed about the invalidity of stereotypes, their propensity to rely on the stereotype is not eliminated and their reliance on individuals' actual information is not increased; and individuals' judgments are particularly prone to distortion by stereotypes in complex, ambiguous situations calling for subjective decisions (Gilovich et al., 2006; Jones, 1997). Why should instructors present material encouraging such powerful, insidious mental processes when the counterbalancing "benefit" is information with extremely limited predictive power?

\section{A FRESH INSTRUCTIONAL APPROACH}

The concerns raised above are recurrently discussed within IB (e.g., Tung, 2008: 45), but changes within the field, if any, are proceeding at glacial speed. So where should teachers of multicultural management turn to improve their courses? We urge them to "look down the hall" to non-IB colleagues teaching social psychology, organizational behavior, and diversity management. IB faculty reaching out in that direction are likely to find colleagues interested in internationalizing their currently U.S.-focused courses in response to increasing interest in workforce diversity management outside the United States (Egan \& Bendick, 2003).

Our suggested approach to collaboration would replace both U.S.-oriented courses in diversity management and IB-based courses in multicultural management with a single course. That merged course would be more likely to become required for all business students-which the importance of its subject certainly justifies.

A merged course should be built on a broad definition of diversity as "real or perceived differences among people that affect their interactions and relationships." These differences should then not be analyzed using sweeping generalizations based on either national cultural dimensions or single demographic characteristics but through the lens of "power, dominance, discrimination and control of resources" (Bell, 2007: 452). The emphasis would be on the universality of the concept and its power to transcend both national boundaries and traditional demographic fault lines (Bendick, Egan, \& Lofhjelm, 2001).
Jameson (2007: 199) defines cultural identity as "an individual's sense of self derived from formal or informal membership in groups that transmit and inculcate knowledge, beliefs, values, attitudes, traditions, and ways of life." In this spirit, a broad conception of cultural identity would not privilege either nationality or traditionally prominent demographic characteristics, but instead balance them with components related to vocation, class, geography, philosophy, language, and the social aspects of biology. This perspective emphasizes that even individuals who are members of $a$ society's dominant culture may simultaneously be members of multiple co-cultures (nondominant groups; Folb, 1994: 122). For example, an executive in an American company may share some of the privileges offered by membership in the dominant American White male culture, but he may also identify with co-cultures within U.S. society, such as senior citizens and gay/lesbians.

Our proposed course would then train students to apply this principle that every individual embodies multiple cultures to practical problems at the individual, group, and organizational levels where managers primarily work. In our experience, the conceptual framework already providing such training most directly is cultural competence. A unified course covering both domestic and international diversity built around this concept could effectively develop skills which, as discussed above, the AACSB and others have identified as crucial for today's managers: cultural self-awareness, cultural consciousness, and multicultural leadership. It would better develop such skills than either multicultural management or diversity management courses typically do today.

Furthermore, cultural competence is not currently the central theme of either predecessor course and thus represents neutral territory between the academic disciplines. Thus, for both conceptual and pragmatic reasons, we suggest cultural competence as the unifying theme and title for the merged course.

\section{A PRIMER ON THE CULTURAL COMPETENCE APPROACH}

In cultural competence terminology, a culture is any characteristic of an individual that tends to influence their sense of identity, perceptions, attitudes, and behavior. It thus encompasses within the same framework the "national cultures" on which courses in multicultural management traditionally focus, the demographic characteristics (race/ethnicity, gender, age, disability, etc.) on which diversity courses traditionally focus, and 
the "invisible" dimensions of diversity (professional background, multiple intelligences, employers' corporate cultures) that diversity courses increasingly address.

Training in cultural competence teaches students to analyze individuals as unique, complex combinations of such influences. Thus, the training contradicts the tendency to reduce individuals to the single "average" aspect of their background, whether that single aspect is, for example, that the person is a woman (an issue addressed in diversity management courses) or that the person is German (an issue in addressed in multicultural management courses). Cultural competence training equally equips students to understand that the influence ony characteristic exercises on individuals may vary by the context in which the individuals find themselves (e.g., at home, in a workplace with colleagues with whom the employee shares cultures, or in a workplace with colleagues with whom the individual does not share cultures).

Cultural competence is defined as a "set of congruent behaviors, attitudes, and policies that come together in a system, agency, or among professionals enabling them to work effectively in crosscultural situations" (Cross, Bazron, Dennis, \& Isaacs, 1989: iv-v). It starts with managers' personal cultural intelligence, or ability to operate in a variety of situations over a career, whether they arise from cross-functional assignments within a company, diverse work teams, or foreign postings (Earley \& Mosakowski, 2004: 2). This ability has at least four components (Ang, Dyne, Koh, Ng, Templer, Tay, \& Chondrasekar, 2007: 6-7):

- Metacognitive intelligence. The ability to acquire cultural knowledge, recognize cultural assumptions, understand cultural norms, and perceive others' cultural preferences before and during interactions.

- Cognitive intelligence. Knowledge of economic, legal, values, and social systems in different cultures and subcultures.

- Motivational intelligence. The desire to learn about and function in situations involving cultural differences, based on intrinsic interest and confidence in one's ability to deal with them.

- Behavioral intelligence. The ability to exhibit situationally appropriate verbal and nonverbal actions, including words, tone, gestures and facial expressions, when interacting with people from different cultures.

Thus, cultural intelligence is about using the head (cognitive); heart (motivation); and body (body language) to "tease out of a person's or group's behavior those features that would be true of all people and all groups, those peculiar to this person or this group, and those that are neither universal nor idiosyncratic" (Earley \& Mosakowski, 2004: 1).

\section{ELEMENTS OF THE UNIFIED COURSE}

Our proposed course could be cotaught by faculty from IB and other disciplines or a single faculty member from either background. However, whomever teaches the course needs to be prepared to learn substantial new material because the content needs to be very different from that of either predecessor course. Former instructors of multicultural management would need to broaden their understanding of "culture" beyond IB's traditional focus on static, homogeneous national-level cultures. They must also be ready to "unteach" information biased against the "exotic other," which their students are likely to have encountered in other IB classes.

At the same time, former instructors of traditional diversity management courses would have to broaden their perspectives beyond demographic distinctions important in the U.S. context. This broadening would require more than simply including instructional cases and classroom examples from other nations. More subtly, it might involve, for example, supplementing instruction on race and gender issues in the United States per se with instruction challenging students to understand what such issues have common with issues such as caste in Hindu societies or the marginal status of the Roma in Europe.

The conceptual foundations for both types of broadening are provided by research on the psychological and sociological roots of stereotyping and prejudice such as was cited above. Instructional materials summarizing such research is readily available (e.g., Bell, 2007, chapter 3; Bielby, 2000; Gilovich et al., 2006; Jones, 1997), as is other instructional material focusing more specifically on business managers, work groups and firms (e.g., Johnson, Lenartowicz, \& Apud, 2006). A particularly useful classroom exercise at the beginning of the course would make students aware of their own unconscious biases by taking the free, webbased test of Project Implicit (Project Implicit, 2007).

Books by Earley and Ang (2003) or Mor Barak (2005), which are centered on the cultural competence theme, could serve as a textbook for our proposed course. Material used to train U.S. doctors and social workers to deliver services to culturally diverse individuals (e.g., Cross et al., 1989) may also prove useful. ${ }^{1}$

\footnotetext{
${ }^{1}$ Additional suggestions on specific course content are available in a longer version of this paper at www.bendickegan.com.
} 
Finding instructional time for such new course content will require former instructors of both predecessor courses to select carefully among topics that traditionally have represented a large part of their courses. In particular, diversity management courses often devote substantial instructional time to historical, institutional, and legal aspects of diversity issues prominent in the United States. While some of this material will remain essential to understanding workforce diversity management in U.S.-based businesses, some detailed materials-for example, detailed provisions of U.S. employment law-might have to be delegated to more specialized human resource management elective courses. For their part, multicultural management courses often devote considerable time to international business etiquette-whether to bring flowers rather than wine to dinner in X country, why it is impolite to show the bottom of one's feet in country Y. This material might be left to students to acquire on their own. Other topics, such as market entry strategies for non-U.S. markets, might be dispensable because they overlap IB marketing courses. In the fierce competition for space in crowded course syllabi, instructors will have to make hard choices concerning what materials are essential to the central goal of the unified course: developing students' competence to fathom culture's complex logic (Lifelong Learning, 2004).

\section{THREE CHALLENGES}

The unified course we are proposing would better prepare students as future managers in today's global, diverse business environment. However, instructors following our suggestions should not expect their efforts at curricular change to be easy or popular. They are likely to encounter at least three challenges.

First, colleagues in a faculty member's home department may not be supportive. Cross-departmental, cotaught classes may spark conflicts over enrollments and budgets. Concerns may be raised about maintaining the intellectual distinctiveness of academic disciplines. Untenured faculty members may receive reminders about the careeradvancing importance of teaching and publishing in a recognized academic field. Faculty deeply invested in their own disciplines may skillfully mobilize such concerns to defend the instructional status quo (Navarro, 2008: 118-119).

Second, a substantial amount of work will be required. Reconceptualizing a course from scratch is a major effort, even more so with multiple instructors. But prior to that, former teachers from both predecessor disciplines will have to read and absorb substantial research from the behavioral sciences, as well as reexamine their own biases and cultural assumptions.

Third, students will not necessarily be pleased. Our experience is that students expect crosscultural management courses to require less work than "courses with numbers," to be fun rather than challenging, and certainly not to be uncomfortable. Contradicting these expectations, welltaught courses on cultural competence push students to develop critical thinking skills, confront their own unconscious biases, and deal with ambiguity. In the short run, it would not be surprising if student course evaluation ratings fall until student expectations begin to change. However, after these students enter the workplace, they may silently thank their professors for helping them develop crucial managerial skills.

\section{REFERENCES}

Albers-Miller, N., Sigerstad, T. D., \& Straughan, R. D. 2000. Internationalization of the undergraduate curriculum: Insight for recruiters. Journal of Teaching in International Business, 11(4): 55-80.

AACSB. 2007. Eligibility procedures and accreditation standards for business accreditation. Tampa, FL: Association to Advance Collegiate Schools of Business International.

Ang, S., Dyne, L. V., Koh, C., Ng, K., Templer, K. J., Tay, C., \& Chandrasekar, N. A. 2007. Cultural intelligence: Its measurement and effects on cultural judgment and decision making, cultural adaptation, and task performance. Singapore: Nanyang Technological University.

Ball, D. A., Hendell, H., McCullock, Jr., Frantz, P. L., Geringer, M. J. \& Minor, M. S. 2006. International business: The challenge of global competition, 10th ed. Boston: McGraw Hill/ Irwin.

Bell, M. P. 2007. Diversity in organizations. Mason, OH: Thomson South-Western.

Bendick, Jr., M., Egan, M., \& Lofhjelm, S. 2001. Workforce diversity training: From anti-discrimination compliance to organizational development. Human Resource Planning 24(2): $10-25$.

Bielby, W. 2000. Minimizing workplace gender and racial bias. Contemporary Sociology, 9(1): 120-130.

Boyacigiller, N. A., Goodman, R. A., \& Phillips, M. E. (Eds.). 2003. Crossing cultures: Insights from master teachers. NY: Routledge.

Cant, A. G. 2004. Internationalizing the business curriculum: Developing intercultural competence. The Journal of American Academy of Business, September: 177-182.

Cross, T., Bazron, B., Dennis, K., \& Isaacs, M. 1989. Towards a culturally competent system of care, volume I. Washington, DC: Georgetown University Center for Child and Human Development.

Drever, J. 1952. A dictionary of psychology. Harmondsworth, Midddlesex, UK: Penguin.

Earley, P. C., \& Ang, S. (Eds.). 2003. Cultural intelligence: Indi- 
vidual interactions across cultures. Stanford, CA: Stanford University Press.

Earley, P. C., \& Mosakowski, E. 2004. Cultural intelligence. Harvard Business Review, 82(10): 1-9.

Egan, M. L. \& Bendick, Jr., M. 2003. Workforce diversity initiatives of U.S. multinational corporations in Europe. Thunderbird International Business Review, 45(6): 701-727.

Folb, E. 1994. Who got the room at the top? Issues of dominance and nondominance in intracultural communications. In L. Samovar \& R. Porter, (Eds.), Intercultural communications: $A$ reader: 119-127 Belmont, MA: Wadsworth.

Gilovich, T., Keltner, D., \& Nisbett, R. 2006. Social psychology. New York: Norton.

Graen, G. B. 2006. In the eye of the beholder: Cross-cultural lesson in leadership from Project GLOBE. Academy of Management Perspectives, 20(4): 95-101.

Hambrick, D., \& Chen, M. 2008. New academic fields as admittance-seeking social movements: The case of strategic management. Academy of Management Review, 33(1): 32-54.

Hofstede, G. 1980. Culture's consequences: International differences in work-related values. Thousand Oaks, CA: Sage.

Hofstede, G. 1991. Cultures and organizations: Software of the mind. New York: McGraw-Hill.

House, R., Javidan, M., Dorfman, P., \& Sully de Luque, M. 2006. A failure of scholarship: Response to George Groen's critique of GLOBE. Academy of Management Perspectives, 20(4): 102-114.

House, R., Javidan, M., Hanges, P., \& Dorfman, P. 2002. Understanding cultures and implicit leadership theories across the globe: An introduction to project GLOBE. Journal of World Business, 37(1): 3-10.

Jameson, D. 2007. Reconceptualizing cultural identity and its role in intercultural business communication. Journal of Business Communication, 44(3): 199-235.

Javidan, M., Dorfman, P., Sully de Luque, M., \& House, R. 2006. In the eye of the beholder: Cross cultural lessons in leadership from Project GLOBE. Academy of Management Perspectives, 20(1): 67-99.

Johnson, J. P., Lenartowicz, T., \& Apud, S. 2006. Cross-cultural competence in international business: Toward a definition and a model. Journal of International Business Studies, 37(4): 525-543.

Jones, J. M. 1997. Prejudice and racism, 2 ed. New York: McGrawHill.

Kirkman, B. L., Lowe, K. B., \& Gibson, C. B. 2006. A quarter century of culture's consequences: A review of empirical

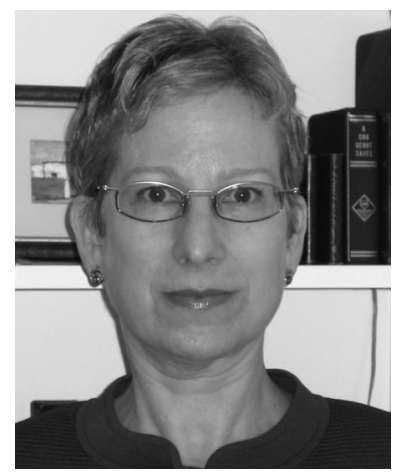

Mary Lou Egan ( $\mathrm{PhD}$, international business) is a cofounder and coprincipal in Bendick and Egan Economic Consultants, Inc., Washington, DC, www .bendickegan.com. A former faculty member in the Department of International Business at George Washington University, she most recently taught multicultural management as a visiting professor at the Helsinki School of Economics. research incorporating Hofstede's cultural values framework. Journal of International Business Studies, 37: 285-320.

Lifelong Learning. 2004. Learning cultural dos and don'ts no longer effective in training global execs, managers. Nov. 13: 1, 3. Stamford, CT: Simba Information.

McSweeney, B. 2002. Hofstede's model of national cultural differences and their consequences: A triumph of faith- $a$ failure of analysis. Human Relations, 55(1): 89-118.

Michigan State University (MSU). 2007. Global edge, International negotiations: Online course module. http://www. globaledge.msu.edu.

Mor Barak, M. E. 2005. Managing diversity: Toward a globally inclusive workplace. Thousand Oaks: Sage.

Navarro, P. 2008. The MBA core curricula of top-ranked U.S. business schools: A study in failure? Academy of Management Learning \& Education, 7: 108-123.

Palich, L. E., Hom, P. W., \& Griffeth, R. W. 1995. Managing in the international context: Testing the cultural generality of sources of commitment to multinational enterprises. Journal of Management, 21(4): 671-690.

Project Implicit. 2007. http://www.projectimplicit.net

Rosenzweig, P. 1994. Note: National culture and management. Boston: Harvard Business School Publishing.

Senyshyn, R. 2002. Cross-cultural competencies in international management curricula: A Delphi study of faculty perspectives. $\mathrm{PhD}$ dissertation, University of Tennessee.

Sivakumar, K., \& Nakata, C. 2001. The stampede toward Hofstede's framework: Avoiding the sample design pit in crosscultural research. Journal of International Business Studies, 32(3): 555-574.

Tipton, F. 2006. Thumbs-up is a rude gesture in Australia: The presentation of culture in international business textbooks. AIB Insights, 6(2): 10-16.

Trompenaars, F. 1994. Riding the waves of culture: Understanding diversity in global business. New York: Irwin.

Tung, R. 2008. The cross-cultural research imperative: The need to balance cross-national and intra-national diversity. Journal of International Business Studies, 39: 41-46.

Wild, J. J., Wild, K. L., \& Han, J. 2006. International business: The challenges of globalization, $3^{\text {rd }}$ ed. Upper Saddle River, NJ: Pearson Education International.

World Bank. 2007. Developing multicultural perspectives: An evaluation of the World Bank's cross-cultural training. Washington, DC: World Bank Institute Evaluation Group.

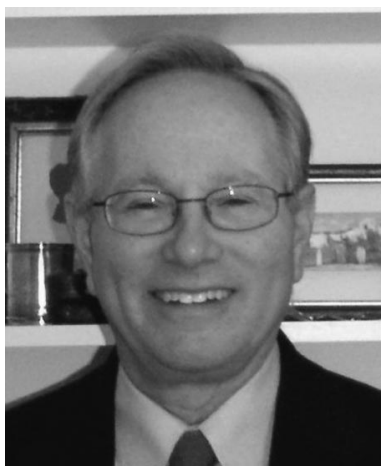

Marc Bendick, Jr. (PhD, economics) is a cofounder and coprincipal in Bendick and Egan Economic Consultants, Inc., Washington, DC, www.bendickegan.com. A frequent expert witness in employment discrimination litigation, his research and consulting focuses on employment opportunities for individuals excluded from the mainstream labor market and best proctices in workforce diversity management. 
Copyright of Academy of Management Learning \& Education is the property of Academy of Management and its content may not be copied or emailed to multiple sites or posted to a listserv without the copyright holder's express written permission. However, users may print, download, or email articles for individual use. 